\title{
Dirofilaria immitis and $D$. repens show circadian co-periodicity in naturally co-infected dogs
}

Angela Monica Ionică ${ }^{1}$, loana Adriana Matei ${ }^{1}$, Gianluca D'Amico ${ }^{1}$, Lucia Victoria Bel ${ }^{2}$, Mirabela Oana Dumitrache ${ }^{1 *}$, David Modrý $y^{3,4,5}$ and Andrei Daniel Mihalca ${ }^{1}$

\begin{abstract}
Background: Dirofilaria immitis and Dirofilaria repens are mosquito-borne zoonotic filarioids typically infecting dogs, causing a potentially fatal cardiopulmonary disease and dermatological conditions, respectively. The females are larviparous, releasing the larvae (microfilariae) into the bloodstream, which further develop in mosquito vectors. However, microfilaremia greatly fluctuates during a 24-h period. As the sampling time can greatly influence the accuracy of diagnosis, the aim of the present study was to assess the circadian periodicity of D. immitis and D. repens in naturally co-infected dogs in an endemic area of Romania and to investigate possible differences of periodicity between these two species.
\end{abstract}

Methods: Overall, four dogs harbouring natural co-infection with D. immitis and D. repens were selected and sampled every two hours for two consecutive days: two dogs in July 2014 and two in July 2015. At each sampling time, a $0.7 \mathrm{ml}$ blood sample was taken. Modified Knott's test was performed on $0.5 \mathrm{ml}$, and the remaining $0.2 \mathrm{ml}$ were used for DNA extraction and molecular amplification, both in single and duplex PCR reactions. Microfilariae of both species were morphologically identified and counted in each collected sample, microfilaremia was calculated, and fluctuation was charted.

Results: The dynamics of microfilaremia showed similar patterns for both Dirofilaria species. In all four dogs, D. immitis was present at all sampling times, with several peak values of microfilaremia, of which one was common for all dogs $(1 \mathrm{am})$, while minimum counts occurred between 5 and $9 \mathrm{am}$. Similarly, for $D$. repens, one of the peak values was recorded in all dogs at $1 \mathrm{am}$, while minimum counts (including zero) occurred at 9 and $11 \mathrm{am}$. Single species-specific PCR reactions were positive for both $D$. immitis and D. repens in all collected samples, while duplex $P C R$ failed to amplify D. repens DNA in many cases.

Conclusions: Both Dirofilaria immitis and D. repens microfilariae are subperiodic, following a similar variation pattern, with peak values of microfilaremia registered during the night in Romania. Duplex PCR fails to identify the infection with $D$. repens in co-infected dogs when the ratio of microfilaremia is in favour of $D$. immitis.

Keywords: Periodicity, Microfilariae, Co-infection, Dirofilaria immitis, Dirofilaria repens

\footnotetext{
* Correspondence: mirabela.dumitrache@usamvcluj.ro

'Department of Parasitology and Parasitic Diseases, University of Agricultural

Sciences and Veterinary Medicine Cluj-Napoca, 335700 Cluj-Napoca, Romania

Full list of author information is available at the end of the article
} 


\section{Background}

In Europe, dogs may be infected by various species of filarioids (Spirurida, Onchocercidae). Among these, veterinary attention has been focused mostly on Dirofilaria immitis, the heartworm, which poses a great risk to animal health, as it is associated with a potentially fatal cardiopulmonary disease [1]. A second species of zoonotic importance is $D$. repens, which resides in the subcutaneous tissues of the canine host and infection is frequently asymptomatic or associated with a series of dermatological conditions [2, 3]. Both species are regarded as zoonotic agents, but $D$. repens is more commonly reported in humans throughout Europe [4, 5]. The female nematodes are larviparous, releasing blood-circulating microfilariae, which are ingested and later transmitted by several genera of mosquitoes (Culex, Aedes and Anopheles) which act as intermediate host and vector [5]. However, in the case of both species, the number of microfilariae present in the peripheral blood fluctuates during the day, according to several potential factors, including geographic origin, and it is assumed that microfilariae concentrate in the lung vessels during the low peripheral microfilaremia phases [6].

The impact of Dirofilaria spp. on animal and human health is recognised throughout Europe, particularly given the recent geographical expansion of both species [7, 8]. However, the level of awareness in non-endemic or newly endemic territories is still low [9]. Furthermore, in many clinical facilities, diagnosis is based solely on the microscopic detection of microfilariae, which may yield falsenegative results, due to several factors, including the intermittent presence of microfilariae in the peripheral blood, or identification of only one species in co-infected animals $[10,11]$. As the risk of human infection is directly related to the populations of infected dogs, particularly in areas where abundant vector populations are present [12], an accurate diagnosis is crucial for the disease control.

As some areas of Romania are endemic for both Dirofilaria species and mixed infections are common [13], while the level of awareness is still low, the necessity of establishing the optimum sampling time to avoid false negativity of diagnostic tests becomes evident. The aims of the present study were to assess the circadian periodicity of $D$. immitis and $D$. repens microfilariae in naturally co-infected dogs in an endemic area of Romania and to investigate possible differences of larval periodicity between the two species.

\section{Methods}

The study was conducted in July 2014 and July 2015 in Chilia Veche (45.421944N, 29.289722E), a rural locality in the Danube Delta region of Romania. Previously, 70 privately owned dogs were tested for the presence of filarioid infection by using modified Knott's test [14]. Four of the dogs which had $D$. immitis and $D$. repens co-infection were enrolled in the experiment after receiving consent from the owner, as follows: $\operatorname{dog} 1$, a 12 year-old castrated male and $\operatorname{dog} 2$, a 4 year-old male were sampled in July 2014; dog 3, a 5 year-old male and $\operatorname{dog} 4$, a 2 year-old male were sampled in July 2015. All dogs were medium-sized mixed breed, lived exclusively outdoors, never travelled and did not receive any antiparasitic treatments. To avoid excessive stress, $32 \mathrm{~mm} \mathrm{G20}$ venous catheters were inserted into the cephalic vein at the beginning of the sampling. The dogs were sampled at a two hours interval for $48 \mathrm{~h}$ (=24 sampling events per dog). At each sampling time, the active/ sleeping status of the dog was registered and $0.7 \mathrm{ml}$ of blood was taken into labelled EDTA tubes as follows: $0.5 \mathrm{ml}$ of blood was used for modified Knott's test (the $2 \%$ formalin was added in situ), following the standard proportions and procedures [14]; the remaining $0.2 \mathrm{ml}$ volume was stored at $-20{ }^{\circ} \mathrm{C}$ until DNA isolation and amplification. In the modified Knott's test, the volume of the total sediment was measured for each sample, and a $40 \mu \mathrm{l}$ homogeneous fraction was examined under a light microscope (Olympus BX 61; Olympus, Tokyo, Japan). Microfilariae were morphologically identified [14] and counted. Based on the obtained counts, the total and average microfilaremia were calculated. Considering the total average daily counts for each species as $100 \%$ for $24 \mathrm{~h}$, variation charts were generated individually for each species of filarioid, according to sampling time, as a percentage, based on the two days average for the respective sampling time. Genomic DNA was extracted from the remaining $0.2 \mathrm{ml}$ of blood from each sample using a commercial kit (Isolate II Genomic DNA Kit, Bioline, London, UK) according to the manufacturer's instructions. Two types of PCR reactions targeting fragments of the $12 \mathrm{~S}$ rDNA and cox 1 genes were performed both individually for each species and in a duplex for the simultaneous detection of $D$. immitis and $D$. repens DNA, following reaction procedures and protocols described in the literature $[15,16]$. In each reaction set, a positive control (DNA extracted from adult nematodes) and a sample with no DNA were included. PCR products were visualised by gel electrophoresis, and their molecular weight was assessed by comparison to a molecular marker (O'GeneRuler $^{\mathrm{Tm}} 100$ bp DNA Ladder, Thermo Fisher Scientific Inc., Waltham, MA, USA).

Correlations between microfilaremia values and between the results of the Knott test and duplex PCRs were evaluated using Spearman's rank correlation test (http:// www.socscistatistics.com. Accessed September 2016).

\section{Results}

\section{Periodicity of microfilaremia}

The average values of microfilaremia for each dog and sampling time are presented in Table 1. Overall, the dynamics of microfilaremia showed similar patterns for both Dirofilaria species, in all four dogs (Fig. 1). 
Table 1 The average values of microfilaremia at each sampling time

\begin{tabular}{|c|c|c|c|c|c|c|c|c|c|c|c|c|}
\hline & $7 \mathrm{am}$ & $9 \mathrm{am}$ & $11 \mathrm{am}$ & $1 \mathrm{pm}$ & $3 \mathrm{pm}$ & $5 \mathrm{pm}$ & $7 \mathrm{pm}$ & $9 \mathrm{pm}$ & $11 \mathrm{pm}$ & $1 \mathrm{am}$ & $3 \mathrm{am}$ & $5 \mathrm{am}$ \\
\hline \multicolumn{13}{|c|}{ Dog 1 (July 2014) } \\
\hline D.i. & 584 & 56 & 98 & 173 & 245 & 116 & 207 & 288 & 429 & 785 & 261 & 272 \\
\hline D.r. & 252 & 0 & 38 & 30 & 186 & 91 & 116 & 128 & 479 & 568 & 140 & 68 \\
\hline \multicolumn{13}{|c|}{ Dog 2 (July 2014) } \\
\hline D.i. & 5,952 & 7,920 & 14,190 & 9,730 & 13,600 & 10,440 & 8,160 & 7,700 & 11,220 & 12,546 & 6,020 & 2,426 \\
\hline D.r. & 372 & 0 & 258 & 420 & 900 & 840 & 840 & 800 & 550 & 1,722 & 840 & 694 \\
\hline \multicolumn{13}{|c|}{ Dog 3 (July 2015) } \\
\hline D.i. & 2,159 & 4,775 & 5,277 & 6,715 & 5,457 & 4,920 & 3,536 & 3,067 & 4,586 & 6,435 & 4,370 & 3,480 \\
\hline D.r. & 217 & 94 & 262 & 272 & 290 & 575 & 330 & 268 & 396 & 478 & 296 & 338 \\
\hline \multicolumn{13}{|c|}{ Dog 4 (July 2015) } \\
\hline D.i. & 855 & 520 & 680 & 2,750 & 2,170 & 3,990 & 4,275 & 4,025 & 1,780 & 4,795 & 1,395 & 3,752 \\
\hline D.r. & 428 & 182 & 140 & 300 & 298 & 578 & 510 & 595 & 460 & 700 & 360 & 182 \\
\hline
\end{tabular}

Abbreviations: D.i. Dirofilaria immitis microfilariae/ml, D.r. Dirofilaria repens microfilariae/ml

Dirofilaria immitis microfilariae were present in all dogs at all sampling times, with several recorded peak values. One of the peaks ( $1 \mathrm{am})$ was common for all dogs, while others occurred in the morning or afternoon samples. The minimum counts were always recorded in the morning samples, between 5 am and $9 \mathrm{am}$. Similarly to $D$. immitis, one peak value of $D$. repens microfilaremia $(1 \mathrm{am})$ was common for all animals. Other maximum counts occurred differentially in the afternoon and evening samples. Minimum values, including zero counts (dogs 1 and 2) were recorded between 9 am and 11 am

In two dogs, a strong positive and statistically significant correlation between the dynamics of the microfilariae of the two Dirofilaria species was observed $(\operatorname{dog} 1: R=0.853$, $P=0.0004 ; \operatorname{dog} 4: R=0.732, P=0.0067$ ). In the other two dogs, a weak correlation with no statistical significance was noted (dog 2: $R=0.204, P=0.52 ; \operatorname{dog} 3: R=0.195, P=0.54)$.

\section{Molecular assays}

Single species-specific PCR reactions were positive both for $D$. immitis and D. repens DNA in all collected samples, regardless the target gene. The duplex PCR failed to amplify D. repens DNA in certain cases (Additional file 1: Table S1).

In the case of duplex PCR reactions, a statistically significant correlation between the ratio of microfilariae of the two species (D. immitis: $D$. repens) and the false negativity for $D$. repens was noted $(R=0.592, P=0$ for $12 \mathrm{~S}$ rDNA; $R=0.242, P=0.017$ for $\operatorname{cox} 1)$.

\section{Discussion}

The periodicity of microfilariae has been first described for Wuchereria bancrofti in 1879 [6]. Since then, this phenomenon has been observed for several other species of filarioids, including Dirofilaria spp., which seem to have a subperiodic cycle, i.e. microfilariae are always present in the peripheral blood, but in fluctuating concentrations [17].
The present study further suggests the existence of a relatively stable pattern of the circadian periodicity of $D$. immitis and $D$. repens microfilariae in naturally co-infected dogs.

The exact mechanism of periodicity is still unknown, but there are two major theories regarding its occurrence. Some authors consider it in relation to the temporal availability of vectors in the respective geographical area, having a local character [18, 19]. Indeed, reports from various countries seem to support this theory. For $D$. immitis, maximum counts have been recorded at 11 am in Tanzania [20], at $6 \mathrm{pm}$ in England [17], between $7 \mathrm{pm}$ and $9 \mathrm{pm}$ in Korea [21] and between 9 pm and $10 \mathrm{pm}$ in Japan [22]. For Dirofilaria repens, maximum counts have been recorded between 10 pm and 3 am in England [17] and throughout the night in Italy [19]. On the other hand, some authors state that the periodic cycle of the microfilariae is in fact oriented to the 24-h habits of the host and varies according to internal factors. For instance, in dogs infected with $D$. immitis that were forced to be active during the night and slept by day, within one week, microfilaremia values shifted, with maximum counts during the day instead of the night [23]. Experimental studies also seem to support the hypothesis that microfilaremia variates according to intrinsic factors of the host [24]. For both D. immitis and D. repens, microfilaremia rises in anesthetized dogs, in changes of oxygen pressure (in both directions, but more markedly when it decreases) and drops when the animal is hyperventilated [24]. Also, a decrease in the dog's body temperature was followed by a significant drop in the number of microfilariae of D. immitis [23]. During sleep, the body temperature falls, carbon dioxide pressure rises, oxygen pressure decreases, acidity rises, kidneys secrete fewer chlorides, and the adrenals are less active, all of these factors having a potential contribution to the dynamics of microfilaremia [6]. In the present study, in most cases, maximum counts were attained during the night $(1 \mathrm{am})$. This corresponds to the 


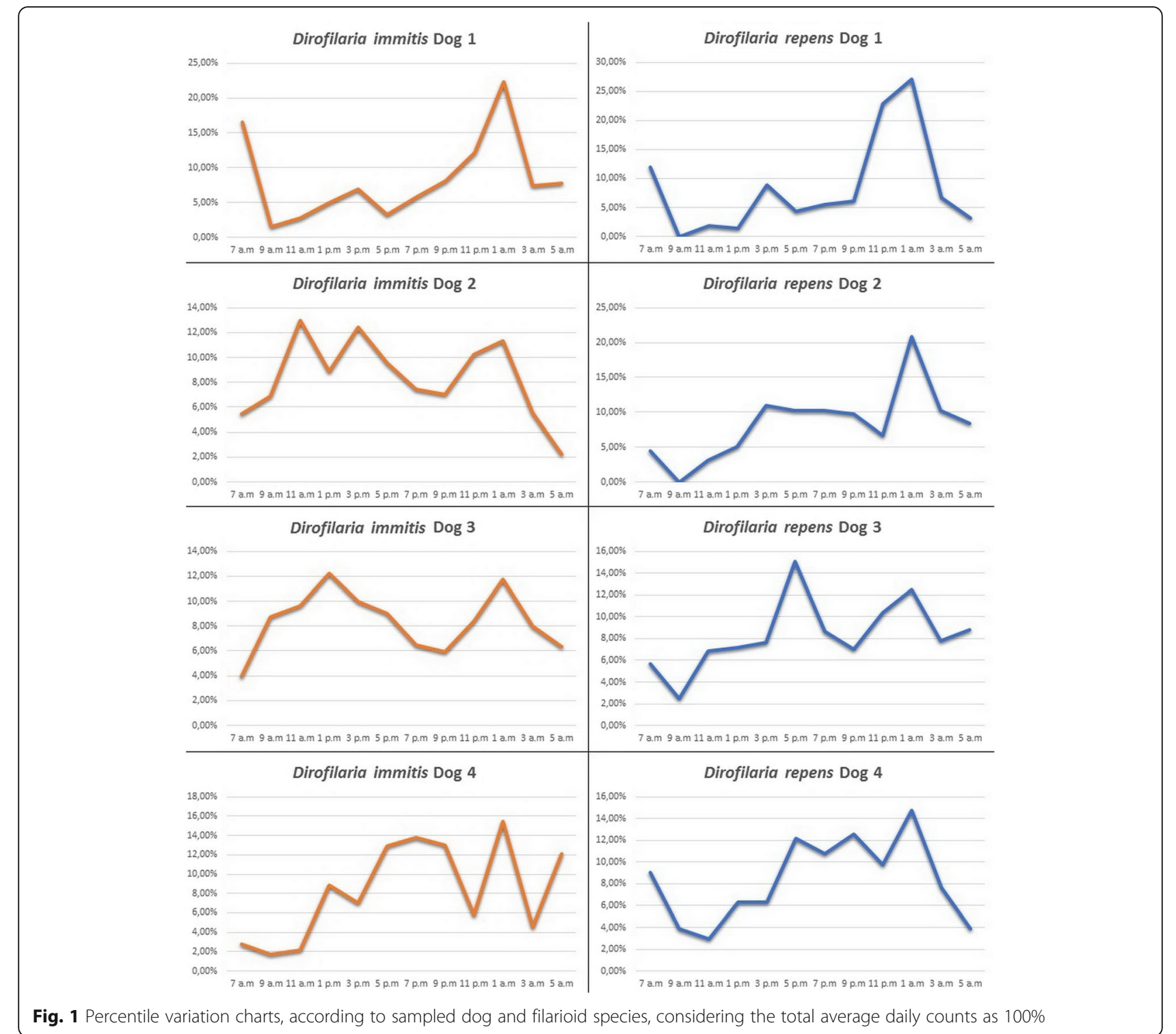

peak biting activity of local mosquito species, such as Culex pipiens, which is an efficient vector for both Dirofilaria spp. and highly attracted to dogs $[25,26]$, but also to the sleeping behaviour of the sampled dogs.

To our knowledge, this is the first periodicity study performed on co-infected dogs. The interspecific relationships between $D$. immitis and D. repens have been only partially studied, suggesting an inhibition of the development of $D$. immitis in dogs previously infected with $D$. repens [27]. However, our results indicate that once the animal develops a patent co-infection, the microfilariae of the two species display a similar circadian periodicity, probably as a reaction to the same stimuli, with no apparent influences between each other.

In many cases, the duplex PCR reactions failed to amplify the DNA of $D$. repens, while species-specific reactions never yielded false negative results. These results were probably due to a preferential amplification of one DNA template over the other, a frequent phenomenon when using multiplex PCRs [28]. The disproportion of microfilariae between the two species was always in favour of $D$. immitis (Tables 1, 2). Therefore, the use of two different species-specific amplification reactions in regions with an unknown epidemiological situation, or if there is a suspicion of co-infection would be advisable.

Ultimately, knowledge regarding the optimum sampling time would greatly decrease the risk of false negative diagnosis, allowing practitioners to initiate proper therapy, thus increasing the chances of survival and the general welfare of infected animals. Not least, an early initiation of microfilaricidal therapy would greatly reduce the spreading of these parasites. 


\section{Conclusion}

Both Dirofilaria immitis and D. repens microfilariae are subperiodic, following a similar variation pattern, with peak values of microfilaremia registered during the night in Romania. Duplex PCR fails to identify the infection with $D$. repens in co-infected dogs when the ratio of microfilaremia is strongly in favour of $D$. immitis, regardless the sampling time. We recommend the use of species-specific PCR or Knott's test, performed on evening/night samples.

\section{Additional file}

Additional file 1: Table S1. The proportion of present microfilariae $(/ \mathrm{ml})$ at each sampling time and results of duplex PCRs. (XLSX $11 \mathrm{~kb}$ )

\section{Acknowledgements}

We are indebted to Petrică Zabara, the owner of the dogs, for his full support and cooperation. We would also like to express our gratitude to Dr Giulio Grandi for providing initial training in the morphological identification of microfilariae at the beginning of the study. The study was performed in the frame of COST Action TD1303, EurNegVeg.

\section{Funding}

This study was supported by the CNCS-UEFISCDI Grant Agency Romania, grant number TE 299/2015.

\section{Availability of data and material}

The data supporting the conclusions of this article are provided within the article and Additional file 1: Table S1.

\section{Authors' contributions}

AMI wrote the initial draft of the manuscript, participated in sampling, and performed morphological identification and counting. IAM, GD and LVB participated in sampling. IAM and AMI performed the molecular assays MOD, DM and ADM coordinated the research and critically revised the manuscript for important intellectual content. All authors read and approved the final manuscript.

\section{Competing interests}

The authors declare that they have no competing interests.

\section{Consent for publication}

Not applicable.

\section{Ethics approval}

The experiments were performed with informed and written consent of the owner of the dogs and were approved by the USAMV Cluj-Napoca Ethics Commission, decision 23/21/09/2015.

\section{Author details}

${ }^{1}$ Department of Parasitology and Parasitic Diseases, University of Agricultural Sciences and Veterinary Medicine Cluj-Napoca, 335700 Cluj-Napoca, Romania. ${ }^{2}$ Department of Anesthesiology and Surgical Techniques, University of Agricultural Sciences and Veterinary Medicine Cluj-Napoca, 335700 Cluj-Napoca, Romania. ${ }^{3}$ Department of Pathology and Parasitology, University of Veterinary and Pharmaceutical Sciences, Brno, Czech Republic. ${ }^{4}$ CEITEC-VFU, University of Veterinary and Pharmaceutical Sciences, Brno, Czech Republic. ${ }^{5}$ Institute of Parasitology, Biology Centre of the Czech Academy of Sciences, České Budĕjovice, Czech Republic.

Received: 15 October 2016 Accepted: 22 February 2017 Published online: 28 February 2017

\section{References}

1. Venco L. Heartworm (Dirofilaria immitis) disease in dogs. In: Genchi C, Rinaldi L, Cringoli G, editors. Mappe Parassitologiche 8 - Dirofilaria immitis and $D$. repens in dog and cat and human infections. Naples: Rolando Editore; 2007. p. 117-25.

2. Tarello W. Clinical aspects of dermatitis associated with Dirofilaria repens in pets: A review of 100 canine and 31 feline cases (1990-2010) and a report of a new clinic case imported from Italy to Dubai. J Parasitol Res. 2011; Article ID 578385; doi:10.1155/2011/578385

3. Albanese F, Abramo F, Braglia C, Caporali C, Venco L, Vercelli A, et al. Nodular lesions due to infestation by Dirofilaria repens in dogs from Italy. Vet Dermatol. 2013;24:255-6.

4. Pampiglione S, Rivasi F. Human dirofilariasis due to Dirofilaria (Nochtiella) repens: an update of world literature from 1995 to 2000. Parassitologia. 2000;42:231-54

5. Otranto D, Dantas-Torres F, Brianti E, Traversa D, Petrić D, Genchi C, Capell G. Vector-borne helminths of dogs and humans in Europe. Parasit Vectors. 2013;6:16

6. Hawking F. Microfilaria infestation as an instance of periodic phenomena seen in host-parasite relationships. Ann NY Acad Sci. 1962;98:940-53.

7. Genchi C, Rinaldi L, Mortarino M, Genchi M, Cringoli G. Climate and Dirofilaria infection in Europe. Vet Parasitol. 2009;163:286-92.

8. Genchi C, Mortarino M, Rinaldi L, Cringoli G, Traldi G, Genchi M. Changing climate and changing vector-borne disease distribution: The example of Dirofilaria in Europe. Vet Parasitol. 2011;176:295-9.

9. Genchi C, Bowman D, Drake J. Canine heartworm disease (Dirofilaria immitis) in Western Europe: survey of veterinary awareness and perceptions. Parasit Vectors. 2014;7:206

10. Genchi C, Venco L, Genchi M. Guideline for the laboratory diagnosis of canine and feline Dirofilaria infections. In: Genchi C, Rinaldi L, Cringoli G, editors. Mappe Parassitologiche 8 - Dirofilaria immitis and D. repens in dog and cat and human infections. Naples: Rolando Editore; 2007. p. 137-44.

11. McCall JW, Genchi C, Kramer LH, Guerrero J, Venco L. Heartworm disease in animals and humans. Adv Parasitol. 2008:66:193-285.

12. Montoya-Alonso JA, Mellado I, Carretón E, Cabrera-Pedrero ED, Morchón R, Simón F. Canine dirofilariosis caused by Dirofilaria immitis is a risk factor for the human population on the island of Gran Canaria, Canary Islands, Spain. Parasitol Res. 2010;107:1265-9.

13. Ionică AM, Matei IA, Mircean V, Dumitrache MO, D'Amico G, Győrke A, et al. Current surveys on the prevalence and distribution of Dirofilaria spp. and Acanthocheilonema reconditum infections in dogs in Romania. Parasitol Res. 2015;114:975-82.

14. Magnis J, Lorentz S, Guardone L, Grimm F, Magi M, Naucke TJ, Deplazes P. Morphometric analyses of canine blood microfilariae isolated by the Knott's test enables Dirofilaria immitis and D. repens species-specific and Acanthocheilonema (syn. Dipetalonema) genus-specific diagnosis. Parasit Vectors. 2013;6:48.

15. Gioia G, Lecová L, Genchi M, Ferri E, Genchi C, Mortarino M. Highly sensitive multiplex PCR for simultaneous detection and discrimination of Dirofilaria immitis and Dirofilaria repens in canine peripheral blood. Vet Parasitol. 2010; 172:160-3.

16. Latrofa MS, Weigl S, Dantas-Torres F, Annoscia G, Traversa D, Brianti E, Otranto D. A multiplex PCR for the simultaneous detection of species of filarioids infesting dogs. Acta Trop. 2012:122:150-4.

17. Webber WAF, Hawking F. Experimental maintenance of Dirofilaria repen and D. immitis in dogs. Exp Parasitol. 1955:4:143-64.

18. Bowman DD, Atkins CE. Heartworm biology, treatment and control. Vet Clin North Am Small Anim Pract. 2009:39:1127-58.

19. Di Cesare A, Otranto D, Di Giulio E, Simonato G, Latrofa MS, La Torre F, et al. Microfilarial periodicity of Dirofilaria repens in naturally infested dogs. Parasitol Res. 2013;112:4273-9.

20. Matola YG. Periodicity of Dirofilaria immitis microfilariae in a dog from Muheza district, Tanzania. J Helminthol. 1991:65:76-8.

21. Rhee JK, Yang SS, Kim HC. Periodicity exhibited by Dirofilaria immitis microfilariae identified in dogs of Korea. Korean J Parasitol. 1998:36:235-9.

22. Nogami S, Murasugi E, Shimazaki K, Maeda R, Harasawa R, Nakagaki K. Quantitative analysis of microfilarial periodicity of Dirofilaria immitis in cats. Vet Parasitol. 2000;92:227-32

23. Aoki Y, Fujimaki Y, Tada I. Basic studies on filaria and filariasis. Trop Med Health. 2011;Supplement 2:51-5.

24. Hawking F. The periodicity of microfilariae. IV. Stimuli affecting the migration of the microfilariae of Dirofilaria aethiops, D. immitis, D. repens, Dipetalonema blanci and Litomosoides carinii. Trans R Soc Trop Med Hyg. 1956;50:397-417. 
25. Nicolescu G, Vladimirescu A, Ciolpan O. The distribution of mosquitoes in Romania (Diptera: Culicidae). Part I: Anopheles, Aedes and Culex. Eu Mosquito Bull. 2002;13:17-26.

26. Capelli G, Frangipane di Regalbono A, Simonato G, Cassini R, Cazzin S, Cancrini $\mathrm{G}$, et al. Risk of canine and human exposure to Dirofilaria immitis infected mosquitoes in endemic areas of Italy. Parasit Vectors. 2013;6:60.

27. Genchi C, Solari Basano F, Bandi C, Di Sacco B, Venco L, Vezzoni A, Cancrini G Factors influencing the spread of heartworms in Italy: interaction between Dirofilaria immitis and Dirofilaria repens. In: Proceedings of Heartworm Symposium '95. Batavia: American Heartworm Society; 1995. p. 65-71.

28. Elnifro EM, Ashshi AM, Cooper RJ, Klapper PE. Multiplex PCR: optimization and application in diagnostic virology. Clin Microbiol Rev. 2000;13:559-70.

Submit your next manuscript to BioMed Central and we will help you at every step:

- We accept pre-submission inquiries

- Our selector tool helps you to find the most relevant journal

- We provide round the clock customer support

- Convenient online submission

- Thorough peer review

- Inclusion in PubMed and all major indexing services

- Maximum visibility for your research

Submit your manuscript at www.biomedcentral.com/submit 